\title{
Editorial Notes
}

The present issue of our journal is a joint one, combining Vol. VI, No. 2 (July-December, 2011) and Vol. VII, No. 1 (January - June, 2012). Our journal is also available in our university web-site (www.nub.ac.com) in the library section. We are getting feedback from readers of the journal; it also shows how many people have accessed the electronic version of the journal. It is quite encouraging.

The issue contains three articles and one book review. The first article is on a set of important issues related to Bangladesh Financial Reporting Standards (BFRS) and environmental accounting in the country. It is based on (secondary) empirical data of 65 manufacturing companies belonging to eight different industrial sub-sectors of food and allied, textiles, pharmaceutical and chemicals, fuel and power, cement, ceramics and so on. The paper examines the strengths and weaknesses of the existing BFRS vis-à-vis the demands for environmental accounting. The paper concludes that the current BFRS are inadequate for self-regulation of the manufacturing sector and monitoring of environmental disclosure. It proposes a mandatory separate statement of environmental assets and liabilities from the manufacturing companies. The second article is on some social aspects of university students of Dhaka city. It is an empirical study based on primary data collected from 120 students (equally divided between male and female) of public and private universities of Dhaka city. The study tries to relate two indicators (estimates) of self-esteem and social responsibility with gender (whether male or female), family type (nuclear or joint) and university type (public or private). By following ANOVA approach, it is found that gender and family type have significant implications for both self-esteem and social responsibility; also it is found that university type has impact on self-esteem. The third paper is on the customer perception of supermarket and its growing demand in Dhaka city. The article is based on a survey of 290 respondents of different age, gender and income groups. It shows that the citydwellers (especially the middle to upper class households) are getting used to shopping at supermarket because of the ease, fixity of prices, quality of goods etc. The journal contains a review of the book, titled "The Long Divergence: How Islamic Law Held Back the Middle East" by Timur Kuran. It is reviewed by William H. Derrenger. It is an enlightening book and so is the review.

We are grateful to the reviewers of our articles. They took so much care in reviewing the articles and gave constructive suggestions in improving the quality of articles. The journal is being produced under the leadership of our Vice-Chancellor Professor M. Shamsul Haque. Ahshan Ullah Bahar has shown his skill in formatting the texts and other related parts of the journal. For any remaining error, the Executive Editor takes responsibility.

\author{
Mahmudul Alam \\ mahmudul_alam46@yahoo.com \\ Executive Editor
}

